\title{
Taxes to Unhealthy Food and Beverages and Oral Health in Mexico: An Observational Study
}

\author{
Mauricio Hernández- $F^{a} \quad$ Alejandra Cantoral $^{a} \quad$ M. Arantxa Colchero ${ }^{b}$ \\ ${ }^{a}$ Center for Research on Nutrition and Health, Instituto Nacional de Salud Pública, Cuernavaca, Mexico; ${ }^{b}$ Center for \\ Health Systems Research, Instituto Nacional de Salud Pública, Cuernavaca, Mexico
}

\section{Keywords}

Dental caries - Taxes · Sugar-sweetened beverages ·

Energy-dense nutrient-poor food · Public dental health

\begin{abstract}
In January 2014, taxes on sugar-sweetened beverages and nonessential energy-dense food were implemented in Mexico to discourage the consumption of these products. Published evaluations have shown reductions in purchases of taxed food and beverages associated with the implementation of this fiscal policy. Although there are some studies on the impact on health based on simulation studies, no evaluations with empirical data on changes in oral health have been published. We used administrative records and data from an epidemiological surveillance system to estimate changes in (1) outpatient visits related to dental caries; (2) having experienced dental caries: Decayed, Missing and Filled Teeth (DMFT) $>0$ for permanent dentition or dmft $>0$ for primary dentition (dmft); (3) number of teeth with caries experience (DMFT and dmft), (4) cases with DMFT >0 or $\mathrm{dmft}$ $>0$, and (5) the series of mean DMFT or dmft, associated with the taxes. We estimated probit and negative binomial models for outcomes at individual level, and interrupted time se-
\end{abstract}

ries analysis for population-level outcomes. The implementation of the taxes was associated with negative changes in the trends of outpatient visits, as well as for cases with DMFT $>0, \mathrm{dmft}>0$ and mean DMFT. Taxes were also associated with a lower probability of having experienced dental caries and with a lower number of teeth with caries experience in the samples studied. Our results suggest positive impacts of the implementation of taxes on unhealthy food and beverages in the oral health of Mexicans, which are the first health benefits observed, and add to the health benefits predicted by modeling studies.

(c) 2021 S. Karger AG, Basel

\section{Introduction}

Mexico is one of the countries with the highest per capita consumption of sugar-sweetened beverages (SSB) in the world [Basu et al., 2013] and the second largest consumer of ultra-processed food and beverages in Latin America [Pan American Health Organization, 2019]. As a consequence, added sugars in Mexico contributed on average with $12.6 \%$ to total energy intake in 2012; SSB accounted for $69 \%$ of these added sugars and food with an 
additional 24\% [Sánchez-Pimienta et al., 2016]. The excessive consumption of SSB and ultra-processed food fails the WHO recommendations to keep the contribution of added sugars to total energy intake below $10 \%$ [World Health Organization, 2015].

Dental caries is a multifactorial disease with socioeconomic [Costa et al., 2012], behavioral and biological determinants [Lee and Brearley Messer, 2011; MartinezMier and Zandona, 2013; Bernabé and Sheiham, 2014]; diet being one of the major risk factors [Bernabé et al., 2015]. Specifically, the intake of free sugars (added sugars plus sugars naturally present in honey, syrups, fruit juices and fruit juice concentrates) at frequent time intervals has been pointed out as the major dietary risk factor in the pathogenesis of dental caries [Burt et al., 1988; Holt, 1991; World Health Organization, 2017]. Therefore, the WHO recommendation to keep the consumption of added sugars below $10 \%$ arose not only because of its association with poor dietary quality, obesity and risk of noncommunicable diseases, but also for its contribution to dental caries [World Health Organization/Food and Agriculture Organization, 2003; World Health Organization, 2015]. Since it is rarely fatal, dental caries is often overlooked in middle-income countries [Executive Board, 2006], although it is the most prevalent condition in the 2015 Global Burden of Disease Study [Vos et al., 2016].

The prevalence of untreated caries is $77.7 \%$ in the population below 19 years old and $92.6 \%$ among adults [Secretaría de Salud, 2018]. Preventing dental caries is important because severe cases can lead to infection, pain, and ultimately tooth extraction, affecting overall health and wellbeing [World Health Organization, 2017]. Dental care prevention has also proven to be a cost-effective intervention [Fraihat et al., 2019]. Despite the implementation of public health programs in Mexico since 1981, such as the promotion of oral hygiene or salt fluoridation, dental caries is still a public health problem that requires other public health policies for prevention [Presidencia de la República, 1981; Irigoyen and Sánchez-Hinojosa, 2000; Irigoyen et al., 2012; Bernabé et al., 2015; World Health Organization, 2017].

Since January 2014, Mexico implemented an $8 \%$ tax to nonessential energy-dense food and a one peso per liter tax to SSB. Taxed beverages include all non-alcoholic beverages with added sugar. Taxed food includes chips and deep-fried salted snacks, sugar confectionery, chocolates, crème caramel and puddings, candied fruits, peanut and hazelnut spreads, caramel sauces, cereal-based sweet foods, ice cream and popsicles, provided they have an energy density $\geq 275 \mathrm{kcal} / 100 \mathrm{~g}$. All these products are com- mon sources of added sugars [Sánchez-Pimienta et al., 2016].

Impact evaluations have proven the effectiveness of the fiscal policies implemented in Mexico: 2 years after its implementation, taxes reduced SSB household purchases by $7.6 \%$ on average [Colchero et al., 2017]; while for taxed food the reduction was around $5 \%$ on the first and 3 years after [Batis et al., 2016; Hernández-F et al., 2019]. Published papers on the potential impact of these taxes on health are based on simulation models [Sánchez-Romero et al., 2016; Barrientos-Gutierrez et al., 2017]. There is a lack of studies about the short-term effects on health outcomes, such as oral health conditions.

The objective of this study was to estimate changes in oral health outcomes associated with the implementation of the taxes in Mexico. We analyzed the following outcomes: outpatient visits, dental caries and number of teeth with dental caries experience.

\section{Materials and Methods}

We used two sources of information. The first data set comes from administrative records on oral outpatient visits for the population without social security provided by public health facilities from the Ministry of Health, which represent approximately half of the Mexican population. The data are managed through an information system called "Dynamic Cubes". Although the data set does not provide information on oral health status, we identified outpatient visits that could be related to dental caries. The second source of information provides data on oral health reported to the Epidemiological Surveillance System of Oral Pathologies (SIVE$\mathrm{PAB}$ by its acronym in Spanish), which tracks 452 sentinel units that belong to any of the institutions that make up the health system and that are fully or partially financed by public resources.

\section{Sources of Information and Outcomes}

Oral Health Outpatient Visits (Dynamic Cubes)

The Ministry of Health collects monthly information on outpatient visits through Dynamic Cubes [Secretaría de Salud, 2019], which is uploaded to the system by the state health ministries and validated by the national Ministry of Health. Validated data covered the period between 2007 and 2018 .

We analyzed outpatient visits that include first and subsequent visits. From the 36 reasons listed for outpatient visits in the data set, with assistance of an oral health practitioner, we selected those more likely related to dental caries: amalgam or resin fillings, extractions of primary or permanent teeth, pulp therapy, and pharmacotherapy.

\section{Dental Caries (SIVEPAB)}

The SIVEPAB is the system that monitors the state of oral health in Mexico, which tracks sentinel medical units distributed in each of the 32 states since 2009. Dentists responsible in each sentinel unit report information related to patients receiving dental treatment for the first time in the year; they conduct diagnostic 
procedures and criteria recommended by the WHO and described in the Manual of Standardized Procedures for Epidemiological Surveillance of the Sentinel Unit Dentist [Secretaría de Salud, 2018]. They fill a unique format and upload the information to the SIVEPAB. The Ministry of Health is responsible for reviewing and integrating the information into annual aggregated databases. The information available in the SIVEPAB covers the period between 2009 and 2018.

The SIVEPAB reports various indices, such as the Decayed, Missing due to caries and Filled Teeth index for permanent dentition (DMFT), which is the number of teeth with caries, and the equivalent index for primary dentition $(\mathrm{dmft})$. DMFT ranges from 0 to 32 and dmft from 0 to 20 . The WHO recommends these indices for the assessment of oral health status in relation to dental caries experience in oral health surveys [World Health Organization, 2013].

We excluded cases of individuals older than 12 years for whom the $\mathrm{dmft}$ index was specified, cases of children under 6 years for whom the DMFT index was specified, as well as cases in which the age of the individual exceeded 99 years for considering them implausible. We also excluded children under 1 year of age because the widespread consumption of infant formulas to feed infants in Mexico [Colchero et al., 2015], more than the consumption of taxed food and beverages, could be the leading cause of dental caries. Additionally, we excluded cases of individuals without sex registration. Cases excluded for these reasons account for $0.5 \%$ of the original sample. In addition, we lost 77,828 cases because they had no information on the Simplified Oral Hygiene Index [Greene and Vermillion, 1964], a relevant variable to adjust the models at individual level. Our analytical sample was of 2,648,893 individuals. Details on the analytical sample can be found in the online supplementary Table S1 (see www.karger.com/doi/10.1159/000515223).

\section{Statistical Analyses}

Oral Health Outpatient Visits

To estimate the association between taxes and oral health outpatient visits, we used Interrupted Time Series Analysis (ITSA) [Linden, 2015]. This approach has been followed to evaluate the effectiveness of population-level health interventions that have been implemented at a clearly defined point in time, in the absence of an experimental design [Lopez et al., 2016], as is the case of the taxes implemented in Mexico in January 2014. Changes in oral health outpatient visits could be associated, in addition to the taxes, with other demographic, seasonal and budgetary factors. We adjusted the models for population growth, binary variables for each month of the year and per capita public health spending for the population without social security.

Despite the adjustment for other variables in time series analysis, random errors may be correlated over time, what is known as autocorrelation [The Pennsylvania State University, 2018]. The autocorrelation order of a series is the number of immediately preceding values in the series, relevant to predict their value in the present [The Pennsylvania State University, 2018]. We applied the Cumby-Huizinga general test to the estimated models to assess autocorrelation [Cumby and Huizinga, 1992], using a user-written program that allows simultaneous testing for several orders of autocorrelation [Baum and Schaffer, 2013]. We explored autocorrelation structure for up to 24 months. When we detected an autocorrelation of order $\geq 1$, we re-estimated the ITSA model controlling for the maximum lag with statistically significant autocorrelation at 5\% significance level [Linden, 2015].

To test the robustness of the results, we estimated the model for an outcome that should not be affected by the taxes. We estimated an ITSA model for preventive oral outpatient visits, not related to caries, as a falsification test. Preventive visits not related to caries include: review of prosthetic hygiene, review of oral tissues and topical application of fluoride. We also performed falsification tests for outpatients and preventive visits by deliberately modifying the implementation year to 2012.

\section{Dental Caries}

With individual-level information from the SIVEPAB, we estimated a probit model for having experienced dental caries for various age strata based on temporary or permanent dentition as a function of a binary variable indicating the year the taxes were implemented. For groups of 1-5 years and 1-12 years, we defined the outcome of having experienced dental caries as $\mathrm{dmft}>0$, while for groups 6-19, 20 or more and 30 or more years, as DMFT $>0$. In addition, we estimated a probit model for the probability of relatively more severe dental caries (DMFT $>3$ ) in the group of 12-year-old children, because this was an indicator for oral health by the year 2000 [International Conference on Primary Health Care. Alma-Ata., 1978], and this stratum is a typical reference for children [World Health Organization, 2013]. We adjusted the model for sociodemographic, socioeconomic and behavioral variables, including the month of diagnosis, region (northern; central; southern), age group (1-5 y; 6-12 y; 13-19 y; 20-65 y, 66-99 y), education level (elementary or lower; junior/ high school or equivalent; undergraduates/graduates; not specified), sex (male; female), affiliation institution, per capita public health spending for the publicly funded health system, and the Simplified Oral Hygiene Index. The latter is a continuous variable which assigns zero to proper hygiene and 6 to the cases with abundant presence of debris in the oral cavity. Additionally, models for adults were adjusted for occupation (professionals and technicians; low-skilled employees; workers without paid employment; students). Given the possibility of cluster effects per medical unit because medical units may not have the same equipment, or the responsible dentist may not be strictly following diagnostic practices, we adjusted for potential intragroup correlation at the medical unit.

We estimated negative binomial models for the number of teeth with caries experience that are used to handle overdispersion in count data. Several studies have shown that the number of teeth with caries experience has overdispersion [Preisser et al., 2012]. We compared mean and variance for $\mathrm{dmft}$ and DMFT by year in our data and found a moderate overdispersion between 18 and $26 \%$.

In addition, we built quarterly series, using the date when the instrument to collect information was applied to patients receiving dental treatment for the first time in the year. We constructed two series: one for the number of individuals having experienced caries (DMFT $>0$ for permanent dentition and $\mathrm{dmft}>0$ for primary dentition) and a second series using average DMFT and dmft indices, calculated for the age groups of 6 or more years or up to 12 years, respectively. We analyzed the series using ITSA models adjusting for binary variables for each quarter, population growth, and per capita spending on institutions that are fully or partially funded from the public budget. 
Table 1. Changes in oral health outpatient visits before and after the taxes were implemented

\begin{tabular}{lcc}
\hline & Coefficient (SE) & \\
\cline { 2 - 3 } & $\begin{array}{l}\text { outpatient visits related } \\
\text { to dental caries }\end{array}$ & $\begin{array}{l}\text { preventive outpatient visits } \\
\text { for oral health (falsification test) }\end{array}$ \\
\hline $\begin{array}{l}\text { Pre-tax trend } \\
\text { Intercept change }\end{array}$ & $-88.1(367.1)$ & $297(665.8)$ \\
Post-tax trend change & $-2,920.5(592.1)^{* *}$ & $136,402.6(22,124.6)^{* *}$ \\
\end{tabular}

** Significant at $1 \%$; ${ }^{*}$ significant at $5 \% ;{ }^{+}$significant at $10 \%$. Author analyses using monthly oral outpatient and preventive visits at facilities from the Ministry of Health, 2007-2018. Interrupted time series analyses adjusted for population growth, binary variables for each month of the year and per capita public health spending. Maximum lag for autocorrelation: 16 for outpatient visits and 4 for preventive visits.

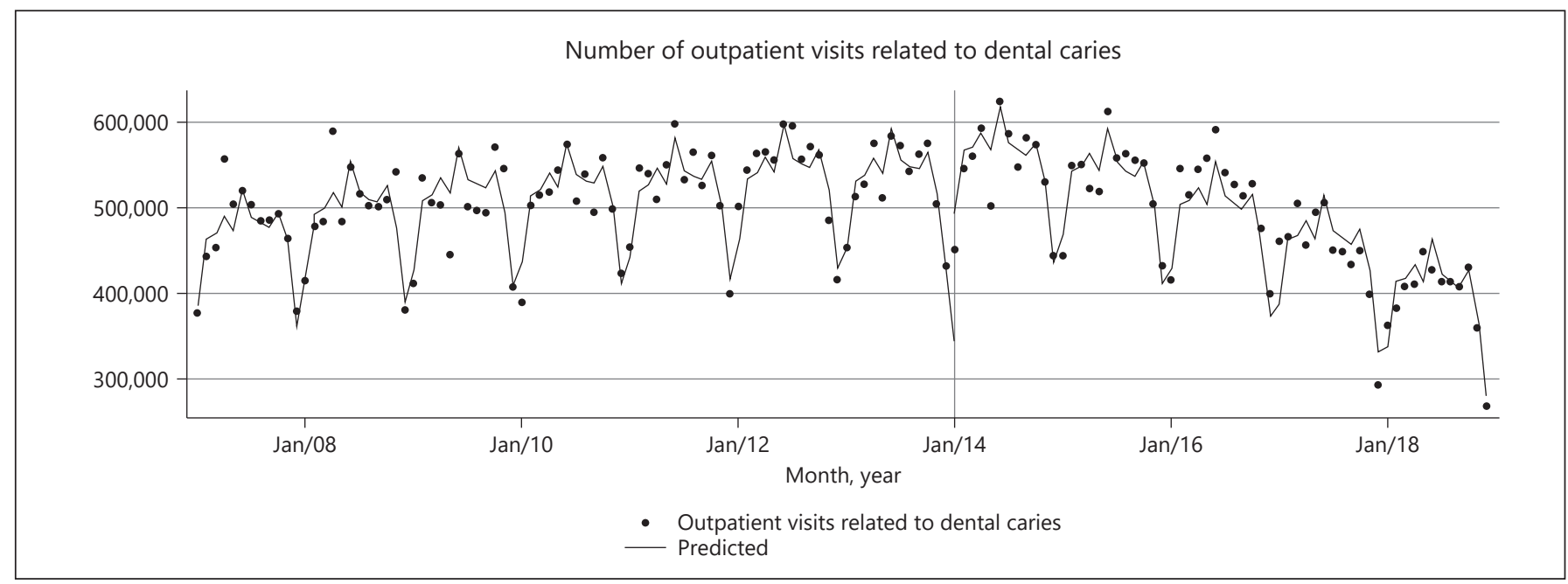

Fig. 1. Oral health outpatient visits related to complications of untreated caries during the period 2007-2018: unadjusted and predicted values.

We considered the results statistically significant at conventional levels (1, 5, 10\%). We performed all analyses in STATA 13 [STATA Corp., 2013].

\section{Results}

\section{Oral Health Outpatient Visits}

Figure 1 shows the number of outpatient visits related to dental caries. The vertical line identifies the time when the taxes were implemented. The dots represent the unadjusted/observed data and the lines are the predicted values from the estimated ITSA model. The graph shows a clear annual seasonality, with an almost constant trend before the implementation of taxes, and decreasing thereafter.
Table 1 shows the results of the ITSA models. For outpatient visits, there was a negative pre-tax trend showing a non-statistically significant average reduction of 88.1 visits per month (significant at $10 \%$ ), an immediate positive change (intercept change) after the taxes were implemented of 41,197 visits, followed by a negative post-tax trend showing an average reduction on the number of outpatient visits of 2,920.5 per month. In contrast, for preventive outpatient visits (falsification test), there was an immediate increase of $136,402.6$ visits but the post-tax trend was not statistically significant suggesting that the taxes had no impact on preventive visits unrelated to dental caries.

Table 2 shows the results of the falsification test using January 2012 as the time that taxes were implemented. For outpatient visits, there is a statistically significant in- 
Table 2. Falsification tests for changes in oral health outpatient visits before and after the taxes were implemented (hypothetical intervention in January 2012)

\begin{tabular}{lll}
\hline & Coefficient (SE) & \\
\cline { 2 - 3 } & $\begin{array}{l}\text { outpatient visits } \\
\text { related to dental caries }\end{array}$ & $\begin{array}{l}\text { preventive outpatient } \\
\text { visits for oral health }\end{array}$ \\
\hline $\begin{array}{lll}\text { Pre-tax trend } \\
\text { Intercept change }\end{array}$ & $-909.1(700)$ & $-726.6(1,435.9)$ \\
Post-tax trend change & $4,696.6(17,533.8)^{* *}$ & $2,136.4(36,059)$ \\
& $-946.0(807.4)$ & $1,901.5(1,639.8)$ \\
\hline
\end{tabular}

** Significant at $1 \% ;{ }^{*}$ significant at $5 \%{ }^{+}$significant at $10 \%$. Author analyses using monthly oral outpatient and preventive visits at facilities from the Ministry of Health, 2007-2018. Interrupted time series analyses adjusted for population growth, binary variables for each month of the year and per capita public health spending. Maximum lag for autocorrelation: 8 for outpatient visits and 8 for preventive visits.

Table 3. Probability of having experienced dental caries and number of teeth with caries experience for temporary and permanent dentition before and after the taxes were implemented

\begin{tabular}{|c|c|c|c|c|}
\hline \multirow[t]{2}{*}{ Age group } & \multicolumn{2}{|c|}{$\begin{array}{l}\text { Probability of having } \\
\text { experienced dental caries }\end{array}$} & \multicolumn{2}{|c|}{$\begin{array}{l}\text { Number of teeth with } \\
\text { caries experience }^{2}\end{array}$} \\
\hline & outcome & AME (SE) & outcome & AME (SE) \\
\hline $1-5$ years & $\mathrm{dmft}>0$ & $-0.005(0.012)$ & $\mathrm{dmft}$ & $-0.105(0.115)$ \\
\hline $1-12$ years & $\mathrm{dmft}>0$ & $-0.022(0.009)^{*}$ & $\mathrm{dmft}$ & $-0.209(0.057)^{* *}$ \\
\hline 12 years & $\mathrm{DMFT}>3$ & $-0.037(0.009)^{* *}$ & DMFT & $-0.298(0.079)^{* *}$ \\
\hline $6-19$ years & DMFT $>0$ & $-0.028(0.006)^{* *}$ & DMFT & $-0.305(0.062)^{* *}$ \\
\hline 20 years or more & $\mathrm{DMFT}>0$ & $-0.021(0.003)^{* *}$ & DMFT & $-0.573(0.119)^{* *}$ \\
\hline 30 years or more & $\mathrm{DMFT}>0$ & $-0.017(0.003)^{* *}$ & DMFT & $-0.643(0.118)^{* *}$ \\
\hline
\end{tabular}

** Significant at $1 \%{ }^{*}$ significant at $5 \% ;^{+}$significant at $10 \%$. Author analyses using oral health data from sentinel medical units reported in the SIVEPAP, 2009-2018. ${ }^{1}$ Probit models, ${ }^{2}$ negative binomial models, both adjusted for population growth, month of diagnosis, region, education, sex, affiliation, the simplified oral hygiene index and per capita public health spending. dmft, temporary dentition, DMFT, permanent dentition.

crease of 4,696.6 just after the taxes were implemented but the post-tax trend was not significant. For preventive visits, none of the coefficients of interest were statistically significant.

\section{Dental Caries}

Table 3 shows the results of the analyses based on the SIVEPAB data at the individual level, for relevant age groups. There are no differences before and after the implementation of taxes in the probability of having experienced dental caries or the number of teeth with caries experience in the age group of $1-5$ years. However, there is a reduction in both outcomes in all age groups when it comes to permanent dentition: $3.7 \%$ for 12 years old, $2.8 \%$ for children between 6 and 19 years old, 2.1\% for adults over 20 years old and $1.7 \%$ for adults over 30 years old. Mean number of teeth decreased by 0.209 for children be- tween 1 and 12 years old, 0.298 for 12 years old, 0.305 for children between 6 and 19 years old, 0.537 for adults over 20 years old and 0.643 for adults over 30 years old.

Table 4 shows changes in the number of individuals having experienced dental caries from the ITSA models. For $\mathrm{dmft}$, we see an immediate reduction of 2,162.9 individuals and an average post-tax reduction of 107.5 individuals having experienced dental caries per quarter. For DMFT, the results show an immediate reduction in the number of individuals experiencing dental caries of 6,147.5 and a post-tax trend reduction of 393.6 individuals per quarter. Figure 2 graphically displays unadjusted and predicted values from the model.

Table 5 shows changes in the mean number of teeth with caries experiences from the ITSA models. For $\mathrm{dmft}$, the results show an immediate reduction of 0.146 in the mean number of teeth with caries after the tax was implemented 
Table 4. Changes in the number of individuals having experienced dental caries for temporary and permanent dentition, before and after the taxes were implemented

\begin{tabular}{lcl}
\hline & Coefficient (SE) & \\
\cline { 2 - 3 } & $\begin{array}{l}\text { individuals with } \\
\mathrm{dmft}>0, \text { ages } \leq 12\end{array}$ & $\begin{array}{l}\text { individuals with } \\
\text { DMFT }>0 \text {, ages } \geq 6\end{array}$ \\
\hline Pre-tax trend & $-8.8(137)$ & $-1,135.6(747.3)$ \\
Intercept change & $-2,162.9(286.6)^{* *}$ & $-6,147.5(1,563.1)^{* *}$ \\
Post-tax trend change & $-107.5(36.5)^{* *}$ & $-393.6(128.9)^{* *}$ \\
\hline
\end{tabular}

** Significant at $1 \%$; ${ }^{*}$ significant at $5 \%$; ${ }^{+}$significant at $10 \%$. Author analyses using oral health data from sentinel medical units reported in the SIVEPAP, 2009-2018. Interrupted time series analyses adjusted for population growth, binary variables for each quarter of the year, per capita public health spending. Maximum lag for autocorrelation $0 . \mathrm{dmft}$, temporary dentition; DMFT, permanent dentition.

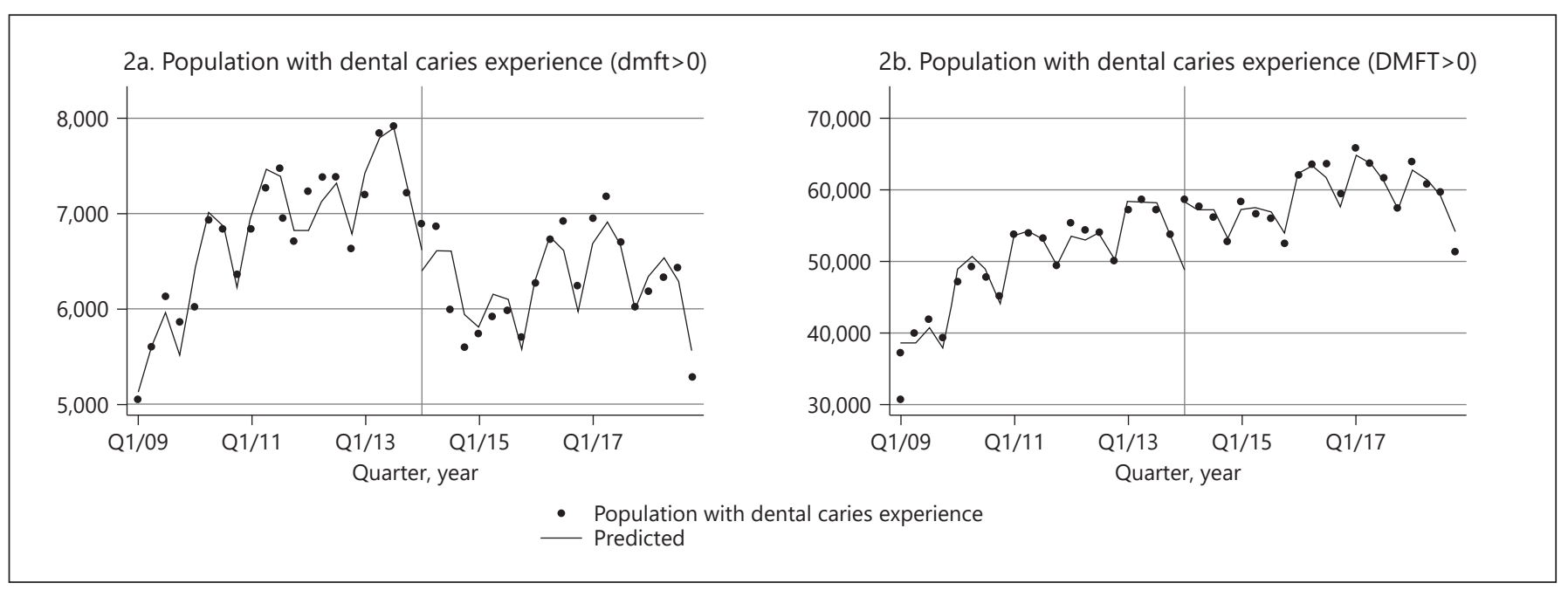

Fig. 2. Population with dental caries experience during the period 2009-2018: unadjusted and predicted values.

and a negative post-tax trend with an average reduction of 0.004 per quarter in the mean number of teeth with caries (significant at $10 \%$ ). For DMFT, the results show a negative post-tax trend with an average quarterly reduction of 0.026 in the mean number of teeth with caries. Figure 3 graphically displays the unadjusted and predicted values from the model (Fig. 3a for average $\mathrm{dmft}$ score in primary dentition and Fig. $3 \mathrm{~b}$ for DMFT score in permanent dentition).

\section{Discussion}

We estimated changes in several oral health outcomes associated with the implementation of the taxes in Mexico. Our results show monthly reductions in the post-tax period for outpatient visits related to caries. We also found a reduction in the probability of having experi- enced dental caries for all age groups, except for children under 5 years old and in the number of teeth with caries. We also found immediate reductions after the taxes were implemented for the number of individuals having experienced dental caries and mean number of teeth with caries experiences and decreasing trends thereafter.

No evaluations of fiscal policies to food and beverages on oral health using empirical data have been published. The literature shows some modeling studies for SSB taxes, which commonly assume increases in consumer prices of around 20\% [Schwendicke et al., 2016; Briggs et al., 2017; Sowa et al., 2018; Jevdjevic et al., 2019; Urwannachotima et al., 2020]. Although the magnitude of the changes in oral health between studies is not comparable with our study given the different assumptions made in each model, all studies predicted positive effects on dental caries, except for one conducted in Thailand [Urwannachotima et al., 2020]. Differ- 
Table 5. Changes in the mean number of teeth with caries experience for temporary and permanent dentition, before and after the taxes were implemented

\begin{tabular}{lcl}
\hline & \multicolumn{2}{l}{ Coefficient (SE) } \\
\cline { 2 - 3 } & mean dmft, ages $\leq 12$ & $\begin{array}{l}\text { mean DMFT, ages } \\
\geq 6\end{array}$ \\
\hline Pre-tax trend & $0.003(0.002)$ & $0.002(0.007)$ \\
Intercept change & $-0.146(0.011)^{* *}$ & $0.04(0.065)$ \\
Post-tax trend change & $-0.004(0.002)^{+}$ & $-0.026(0.007)^{* *}$ \\
\hline
\end{tabular}

** Significant at $1 \%$; significant at $5 \%$; $^{+}$significant at $10 \%$. Author analyses using oral health data from sentinel medical units reported in the SIVEPAP, 2009-2018. Interrupted time series analyses adjusted for population growth, binary variables for each quarter of the year, per capita public health spending. Maximum lag for autocorrelation 0 for mean $\mathrm{dmft}, 3$ for DMFT. dmft, temporary dentition; DMFT, permanent dentition.

ent assumptions including the magnitude and type of the tax, products covered, pass through prices, as well as the baseline consumption could lead to different results on changes in dental caries. For instance, Mexico has a higher SSB consumption than the countries included in the modeling studies [Singh et al., 2015], we may expect higher positive effects in a setting with higher consumption.

Our results on oral health associated with the taxes are plausible. Consumption of fluoride in Mexico is high in some population groups associated to the high consumption of fluoridated salt, the widespread use of fluoride toothpastes, the consumption of water from sources that naturally have a high concentration of fluoride, and/or the consumption of beverages made from this water [Martínez-Mier et al., 2003]. Fluoride consumption could be protective against dental caries; however, no studies have been conducted on the trends of fluoride intake at the national level and its effect on caries. Even if fluoride intake had a nationwide protective effect against dental caries [Irigoyen and Sánchez-Hinojosa, 2000; Irigoyen et al., 2012], dietary patterns could offset the effect [Burt and Pai, 2001], particularly for a country with high intake of sugar-sweetened beverages [Basu et al., 2013; Popkin and Hawkes, 2016]. Hence our results on changes in oral health are plausible given the evidence of reductions in purchases of taxed food and beverages [Batis et al., 2016; Colchero et al., 2017; Hernández-F et al., 2019], which have a high contribution to added sugar in the diet of Mexicans [Sánchez-Pimienta et al., 2016]. Substitutions for untaxed beverages with added sugar may have been small since the tax covered all beverages with added sug-

Taxes to Unhealthy Food and Oral Health in Mexico ars except $100 \%$ juices. In addition, the evaluation of the tax showed increases in purchases of untaxed beverages, mostly bottle water [Colchero et al., 2016]. Moreover, in the period under study, there were no major changes in public policies with the potential to enhance oral health, since the effective national salt fluoridation program started in 1981 [Presidencia de la República, 1981; Secretaría de Salud, 1995], and in the period 2013-2018, no extraordinary actions were implemented to prevent dental caries [Secretaría de Salud, 2014]. Finally, the followup of 4 years after the taxes were implemented seems adequate to observe a change in dental caries. A study published in 2011 shows significant positive effects on dental caries associated with the United Nations Sanction in Iraq after 5 years of implementation [Jamel et al., 2004].

The lower impact found in outcomes related to dental caries at the individual level on children aged up to 12 years, and especially those under 5 years old, may be explained by several factors associated to dental caries in this age group, including the higher consumption of sugary food and beverages that were not affected by the taxes such as $100 \%$ juices [Stern et al., 2014], the inadequate oral hygiene [Chu et al., 2012], the frequency and the intake of SSB, snacks or sweets with a high cariogenic index [Tinanoff and Palmer, 2000].

Our study has some limitations. We acknowledge that there is not an experimental design as the taxes were implemented at the national level. However, it is possible to make causal inference from observational data using quasi-experimental methods [Listl et al., 2016]. In this paper, we used interrupted time series analyses that allowed us to get estimates adjusting for previous trends in caries rates. A descriptive report on oral health in Mexico between 2005 and 2014 suggests a slight improvement in oral health, mainly among 12-year-old children [Secretaría de Salud, 2015]. These improvements may had happened before the tax period, especially when it comes to primary dentition of children. Our methodological approach adjusts for previous trends and for variables that may be associated with changes in the outcomes of interest over time. Therefore, our findings show that, beyond improvements in specific age groups, taxes have improved the oral health of the general population.

Other limitations of our study relate to the sources of information. The two data sets used in our study are not representative at the national level but they represent a large proportion of the population. The Ministry of Health conducts $54.8 \%$ of the dental outpatient visits of the health system that are fully or partially funded by the public budget [Secretaría de Salud, 2015], and the Dynamic Cubes 


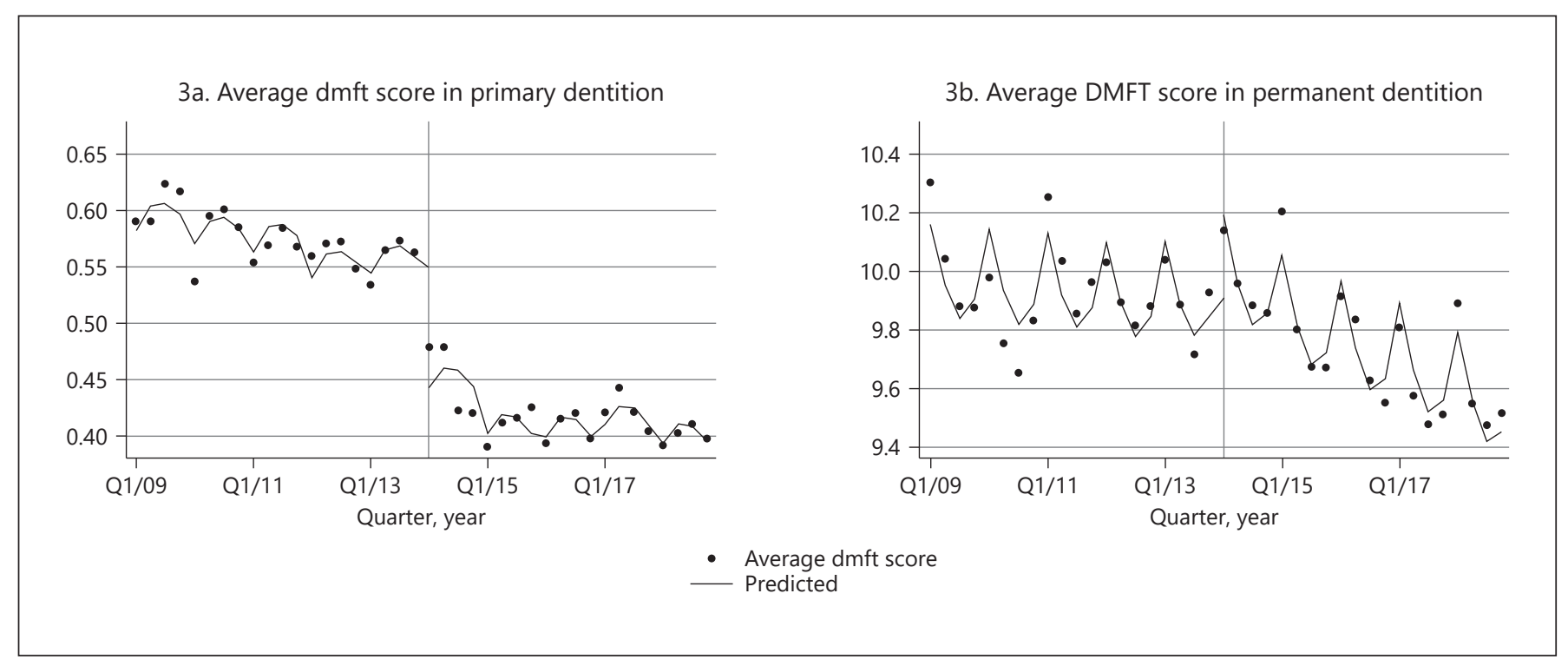

Fig. 3. Mean number of teeth with caries experience during the period 2009-2018: unadjusted and predicted values.

capture all these outpatient visits. The SIVEPAB is representative of the public health system with the exception of the IMSS in its ordinary regime. Another limitation is that data on outpatient visits do not provide information on oral health status. However, because there is evidence of a dose-response relationship between sugar consumption and dental caries, we can expect to see a reduction in oral health outpatient visits [World Health Organization, 2017]. We selected visits of complications more likely related to untreated caries, although we cannot guarantee that all of them are related to dental caries complications.

The last limitation of the data is that we can only observe the population that accesses health services. Access to services may have changed over time, however, there were no reforms in the oral health public health system that could have biased our results.

A limitation of models used in our study to estimate the number of individuals with dental caries is that there is no information on eating habits that could be related to caries. However, we adjusted for an indicator of oral hygiene practices, which is another important predictor of oral health [Petersen, 2003].

Other studies have used indices with greater sensitivity to detect changes in the health status of teeth than DMFT or dmft indices reported in the SIVEPAB such as the Caries Detection and Assessment System [Andrade and De la Cruz, 2014]. It is possible that the tax is only delaying the progression from caries to cavitation but this cannot be studied with the data available in the SIVEPAB.
Despite the limitations, this is the first study that estimated changes in oral health associated with ongoing taxes. We used two sources of information that represent large segments of the Mexican population. We applied different methodological approaches to analyze information at the individual and population level. Our results show statistically significant improvements on caries rates associated with the implementation of the taxes on unhealthy food and beverages, which are the first health benefits observed, and add to the health effects predicted by modeling studies. Higher benefits in caries rates could be expected if in addition to taxation, other cost-effective measures were implemented such as workplace bans to SSB [Basu et al., 2020] and front-of pack labeling [Jevdjevic et al., 2020] which was implemented in Mexico since October 2020 [Secretaría de Economía, 2020].

\section{Statement of Ethics}

This research is based in non-identifiable human data, collected by the Mexican Ministry of Health in accordance with the regulations of the General Health Law on research and the principles of Helsinki.

\section{Conflict of Interest Statement}

The authors have no conflicts of interest to declare. 


\section{Funding Sources}

This work received funding from Bloomberg Philanthropies. Beyond financial support, the funder had no role in the study design, data collection, analyses, interpretation, writing, and in the decision to submit the article for publication.

\section{Author Contributions}

M.H.-F. literature review, data analyses, interpretation of results, writing of the first draft, critical review of the manuscript, approval of the final version. A.C. literature review, interpretation of results, critical review of the manuscript, approval of the final version. M.A.C. conception of the study, literature review, review data analyses, interpretation of results, critical review of the manuscript, approval of the final version.

\section{References}

Andrade M, De la Cruz D. Indicadores de prevalencia y de predicción de riesgo de caries dental. VERTIENTES Rev Espec En Cienc Salud. 2014; 17:61-72

Barrientos-Gutierrez T, Zepeda-Tello R, Rodrigues ER, Colchero MA, Rojas-Martínez R, Lazcano-Ponce E, et al. Expected population weight and diabetes impact of the 1-peso-perlitre tax to sugar sweetened beverages in Mexico. PLoS One. 2017 May;12(5):e0176336.

Basu S, Jacobs LM, Epel E, Schillinger D, Schmidt L. Cost-Effectiveness Of A Workplace Ban On Sugar-Sweetened Beverage Sales: A Microsimulation Model. Health Aff (Millwood) $2020 \mathrm{Jul} ; 39(7): 1140-8$.

Basu S, McKee M, Galea G, Stuckler D. Relationship of soft drink consumption to global overweight, obesity, and diabetes: a cross-national analysis of 75 countries. Am J Public Health. 2013 Nov;103(11):2071-7.

Batis C, Rivera JA, Popkin BM, Taillie LS. FirstYear Evaluation of Mexico's Tax on Nonessential Energy-Dense Foods: An Observational Study. PLoS Med. 2016 Jul; 13(7):e1002057.

Baum CF, Schaffer ME. actest: Stata module to perform Cumby-Huizinga general test for autocorrelation in time series. Statistical Software Components S457668 [Internet]. Dep Econ Boston Coll 2013; Available from: http://ideas.repec.org/c/boc/bocode/ s457668.html.

Bernabé E, Sheiham A. Age, period and cohort trends in caries of permanent teeth in four developed countries. Am J Public Health. 2014 Jul;104(7):e115-21.

Bernabé E, Vehkalahti MM, Sheiham A, Lundqvist A, Suominen AL. The Shape of the Dose-Response Relationship between Sugars and Caries in Adults. J Dent Res. 2016 Feb; 95(2):167-72.

Briggs AD, Mytton OT, Kehlbacher A, Tiffin R, Elhussein A, Rayner M, et al. Health impact assessment of the UK soft drinks industry levy: a comparative risk assessment modelling study. Lancet Public Health. 2016 Dec; 2(1):e15-22.

Burt BA, Pai S. Sugar consumption and caries risk: a systematic review. J Dent Educ. 2001 Oct;65(10):1017-23.

Burt BA, Eklund SA, Morgan KJ, Larkin FE, Guire KE, Brown LO, et al. The effects of sugars intake and frequency of ingestion on dental car- ies increment in a three-year longitudinal study. J Dent Res. 1988 Nov;67(11):1422-9.

$\mathrm{Chu} \mathrm{CH}$, Ho PL, Lo EC. Oral health status and behaviours of preschool children in Hong Kong. BMC Public Health. 2012 Sep;12(1): 767.

Colchero MA, Contreras-Loya D, Lopez-Gatell H, González de Cosío T. The costs of inadequate breastfeeding of infants in Mexico. Am J Clin Nutr. 2015 Mar;101(3):579-86.

Colchero MA, Popkin BM, Rivera JA, Ng SW. Beverage purchases from stores in Mexico under the excise tax on sugar sweetened beverages: observational study. BMJ. 2016 Jan; 352:h6704.

Colchero MA, Rivera JA, Popkin BM, Ng SW. Sustained consumer response: evidence from two-years after implementing the sugar sweetened beverage tax in Mexico. Health Aff (Millwood). 2017;36:564-71

Costa SM, Martins CC, Bonfim ML, Zina LG, Paiva SM, Pordeus IA, et al. A systematic review of socioeconomic indicators and dental caries in adults. Int J Environ Res Public Health. 2012 Oct;9(10):3540-74.

Cumby RE, Huizinga J. Testing the Autocorrelation Structure of Disturbances in Ordinary Least Squares and Instrumental Variables Regressions. Econometrica. 1992;60(1):185-95.

Executive Board 120: Oral health: action plan for promotion and integrated disease prevention [Internet], Geneva, World Health Organization, 2006. Available from: https://apps.who. int/iris/handle/10665/21909.

Fraihat N, Madae'en S, Bencze Z, Herczeg A, Varga O. Clinical Effectiveness and Cost-Effectiveness of Oral-Health Promotion in Dental Caries Prevention among Children: Systematic Review and Meta-Analysis. Int J Environ Res Public Health. 2019 Jul;16(15):E2668.

Greene JC, Vermillion JR. The Simplified Oral Hygiene Index. J Am Dent Assoc. 1964 Jan; 68(1):7-13.

Hernández-F M, Batis C, Rivera JA, Colchero MA. Reduction in purchases of energy-dense nutrient-poor foods in Mexico associated with the introduction of a tax in 2014. Prev Med. 2019 Jan;118:16-22.

Holt RD. Foods and drinks at four daily time intervals in a group of young children. Br Dent J. 1991 Feb;170(4):137-43.

International Conference on Primary Health Care. Alma-Ata. USSR, 1978.
Irigoyen ME, Mejía-González A, Zepeda-Zepeda MA, Betancourt-Linares A, Lezana-Fernández MÁ, Álvarez-Lucas CH. Dental caries in Mexican schoolchildren: a comparison of 1988-1989 and 1998-2001 surveys. Med Oral Patol Oral Cir Bucal. 2012 Sep;17(5):e825-32.

Irigoyen ME, Sánchez-Hinojosa G. Changes in dental caries prevalence in 12-year-old students in the State of Mexico after 9 years of salt fluoridation. Caries Res. 2000 Jul-Aug;34(4):303-7.

Jamel H, Plasschaert A, Sheiham A. Dental caries experience and availability of sugars in Iraqi children before and after the United Nations sanctions. Int Dent J. 2004 Feb;54(1):21-5.

Jevdjevic M, Trescher AL, Rovers M, Listl S. The caries-related cost and effects of a tax on sugar-sweetened beverages. Public Health. 2019 Apr;169:125-32.

Jevdjevic M, Wijn SR, Trescher AL, Nair R, Rovers M, Listl S. Front-of-Package Food Labeling to Reduce Caries: economic Evaluation. J Dent Res. 2020, Online ahead of print.

Lee JG, Brearley Messer LJ. Contemporary fluid intake and dental caries in Australian children. Aust Dent J. 2011 Jun;56(2):122-31.

Linden A. Conducting interrupted time-series analysis for single- and multiple-group comparisons. Stata J. 2015;15(2):480-500.

Listl S, Jürges H, Watt RG. Causal inference from observational data. Community Dent Oral Epidemiol. 2016 Oct;44(5):409-15.

Lopez J, Cummins S, Gasparrini A: Interrupted time series regression for the evaluation of public health interventions: a tutorial. Int J Epidemiol. 2016;46:348-55.

Martínez-Mier EA, Soto-Rojas AE, Ureña-Cirett JL, Stookey GK, Dunipace AJ. Fluoride intake from foods, beverages and dentifrice by children in Mexico. Community Dent Oral Epidemiol. 2003 Jun;31(3):221-30.

Martinez-Mier EA, Zandona AF. The impact of gender on caries prevalence and risk assessment. Dent Clin North Am. 2013 Apr;57(2): 301-15.

Pan American Health Organization. Ultra-processed food and drink products in Latin America: Sales, sources, nutrient profiles, and policy implications, Washington, DC, 2019.

Petersen PE. The World Oral Health Report 2003: continuous improvement of oral health in the 21st century-the approach of the WHO Global Oral Health Programme. Community Dent Oral Epidemiol. 2003 Dec;31 Suppl 1:3-23. 
Popkin BM, Hawkes C. Sweetening of the global diet, particularly beverages: patterns, trends, and policy responses. Lancet Diabetes Endocrinol. 2016 Feb;4(2):174-86.

Preisser JS, Stamm JW, Long DL, Kincade ME. Review and recommendations for zero-inflated count regression modeling of dental caries indices in epidemiological studies. Caries Res. 2012;46(4):413-23.

Presidencia de la República: Reglamento de Yodatacion y Fluoruracion de la Sal 1981.

Sánchez-Pimienta TG, Batis C, Lutter CK, Rivera JA. Sugar-Sweetened Beverages Are the Main Sources of Added Sugar Intake in the Mexican Population. J Nutr. 2016 Sep;146(9):1888S96S.

Sánchez-Romero LM, Penko J, Coxson PG, Fernández A, Mason A, Moran AE, et al. Projected Impact of Mexico's Sugar-Sweetened Beverage Tax Policy on Diabetes and Cardiovascular Disease: A Modeling Study. PLoS Med. 2016 Nov;13(11):e1002158.

Schwendicke F, Thomson WM, Broadbent JM, Stolpe M. Effects of Taxing Sugar-Sweetened Beverages on Caries and Treatment Costs. J Dent Res. 2016 Nov;95(12):1327-32.

Secretaría de Economía. MODIFICACIÓN a la Norma Oficial Mexicana NOM-051-SCFI/ SSA1-2010, Especificaciones generales de etiquetado para alimentos y bebidas no alcohólicas preenvasados-Información comercial y sanitaria, publicada el 5 de abril de 2010 [Internet], 2020, [cited $2021 \mathrm{Feb} 3$ ]. Available from: https://www.dof.gob.mx/nota_detalle. php codigo $=5590668 \&$ fecha $=27 / 03 / 2020$.
Secretaría de Salud: Norma Oficial Mexicana NOM-040-SSA1-1993, 1995.

Secretaría de Salud. Programa de Acción Específico Prevención, Detección y Control de los Problemas de Salud Bucal 2013-2018 [Internet] 2014 [cited $2020 \mathrm{Feb} 24$ ]; Available from: https://www.gob.mx/salud/documentos/ programa-de-accion-especifico-prevenciondeteccion-y-control-de-los-problemas-desalud-bucal-2013-2018.

Secretaría de Salud. Sistema de Vigilancia Epidemiológica de Patologías Bucales, 10 años vigilando la salud bucal de los mexicanos. Ciudad de México; 2015.

Secretaría de Salud. Resultados del Sistema de Vigilancia Epidemiológica de Patologías Bucales SIVEPAB 2018. Ciudad de México; 2018.

Secretaría de Salud. Servicios SIS [Internet] 2019 [cited 2020 Jan 8]; Available from: http:// www.dgis.salud.gob.mx/contenidos/basesdedatos/bdc_serviciossis_gobmx.html.

Singh GM, Micha R, Khatibzadeh S, Shi P, Lim S, Andrews KG, et al.; Global Burden of Diseases Nutrition and Chronic Diseases Expert Group (NutriCoDE). Global, Regional, and National Consumption of Sugar-Sweetened Beverages, Fruit Juices, and Milk: A Systematic Assessment of Beverage Intake in 187 Countries. PLoS One. 2015 Aug;10(8):e0124845.

Sowa PM, Keller E, Stormon N, Lalloo R, Ford PJ. The impact of a sugar-sweetened beverages tax on oral health and costs of dental care in Australia. Eur J Public Health. 2019 Feb; 29(1):173-7.
STATA Corp.: Stata Statistical Software: Release 13, STATACorp LP, 2013.

Stern D, Piernas C, Barquera S, Rivera JA, Popkin BM. Caloric beverages were major sources of energy among children and adults in Mexico, 1999-2012. J Nutr. 2014 Jun;144(6):949-56.

The Pennsylvania State University. Autocorrelation and Time Series Methods | STAT 462 [Internet]. XXX 2018 [cited 2020 Mar 11]; Available from: https://online.stat.psu.edu/ stat462/node/188/.

Tinanoff N, Palmer CA. Dietary determinants of dental caries and dietary recommendations for preschool children. J Public Health Dent. 2000;60(3):197-206.

Urwannachotima N, Hanvoravongchai P, Ansah JP, Prasertsom P, Koh VR. Impact of sugarsweetened beverage tax on dental caries: a simulation analysis. BMC Oral Health. 2020 Mar;20(1):76

Vos T, Allen C, Arora M, Barber RM, Bhutta ZA, Brown A, et al.; GBD 2015 Disease and Injury Incidence and Prevalence Collaborators. Global, regional, and national incidence, prevalence, and years lived with disability for 310 diseases and injuries, 1990-2015: a systematic analysis for the Global Burden of Disease Study 2015. Lancet. 2016 Oct;388(10053): 1545-602.

World Health Organization. Oral health surveys: basic methods. 5th ed. Geneva; 2013.

World Health Organization. Guideline: Sugars intake for adults and children, Geneva, 2015.

World Health Organization: Sugars and dental caries. 2017.

World Health Organization / Food and Agriculture Organization. Diet, nutrition and the prevention of chronic diseases. Report of a joint WHO/FAO expert consultation [Internet], Geneva, WHO, 2003. Available from: http://whqlibdoc.who.int/trs/WHO TRS_916.pdf. 